\title{
Deeper wedge resection and parenchymal- sparing bronchoplasty of the secondary carina: an alternative surgical technique for removal of tumor located at the orifice of upper lobar bronchus
}

\author{
An Wang ${ }^{\dagger}$, Xiaofeng Chen ${ }^{\dagger}$, Dayu Huang and Shaohua Wang ${ }^{*}$
}

\begin{abstract}
Background: Sleeve resection and reconstruction of the bronchial corner between the upper lobar bronchus and the intermediate bronchus is technique demanding.

Case presentation: A 33-year-old Chinese man suffered from recurrence of low-grade malignant mucoepidermoid carcinoma located at the orifice of upper lobar bronchus with invasion to the main bronchus nearly 1 year after he had undergone an incomplete bronchoscopic resection. With detailed preoperative and intraoperative evaluation by computed tomography and bronchoscopy, a deeper wedge resection and bronchoplasty of the secondary carina was performed. The freedom from tumor cells at the cut-edges was guaranteed by frozen examination. The postoperative course was uneventful and the patient was free from recurrence for 18 months after the surgery.

Conclusions: With an RO resection, the procedure described in the present case report was feasible and relatively easy, thus an alternative to sleeve lobectomy or sleeve bronchial resection for small-size low-grade malignancy located at the orifice of upper lobar bronchus.
\end{abstract}

Keywords: Secondary carina reconstruction, Bronchoplasty, Parenchymal-preserving surgery

\section{Backgroud}

Sleeve resection and reconstruction of the bronchial corner between the upper lobar bronchus and the intermediate bronchus is technique demanding with acceptable mortality and morbidity due to improved surgical technique and postoperative care [1]. Here we reported a case of deeper wedge resection and bronchoplasty of the secondary carina for tumors located at the orifice of upper lobar bronchus with main bronchus involvement. The parenchymalsparing surgical technique has not been detailed described in the literatures and was believed to be easier and less time-consuming than sleeve bronchial resection.

\footnotetext{
* Correspondence: wangsh@fudan.edu.cn

${ }^{\dagger}$ Equal contributors

Department of Thoracic Surgery, Huashan Hospital, Fudan University, Shanghai, China
}

\section{Case presentation}

A 33-year old man was admitted with a complaint of exacerbated cough and hemoptysis for nearly one year since he underwent a bronchoscopic procedure for mucoepidermoid carcinoma resection at the orifice of right upper lobar bronchus in his local hospital. After computed tomography (CT) scanning, a mass of $13 \mathrm{~mm}$ in size situated at the junction of the right upper lobar bronchus and main bronchus was found (Fig. 1). Bronchoscopic biopsy confirmed the diagnosis of mucoepidermoid carcinoma recurrence.

Surgical therapy was administered. The patient was placed in the left lateral decubitus position. General anesthesia was induced with a double lumen endotracheal tube in trachea. A $10 \mathrm{~cm}$ muscle-sparing incision was made in the fifth intercostal space. Firstly, hilar lymph nodes (\#10), inter-lobar lymph nodes (\#11 s) and the 


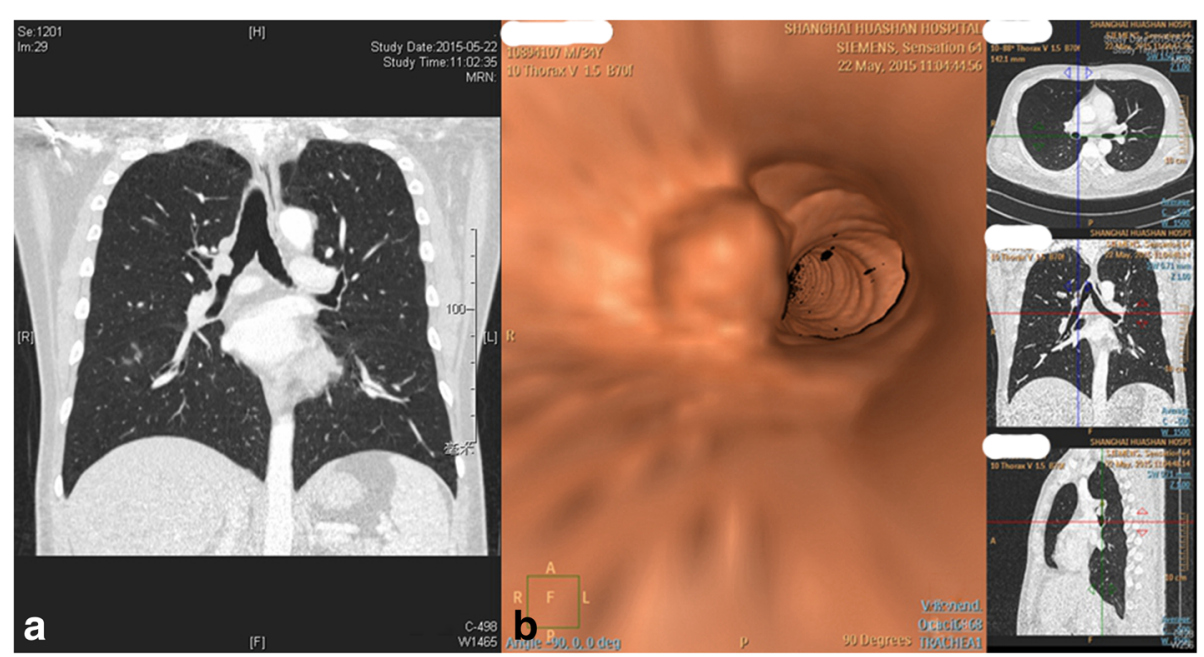

Fig. 1 a Multi-planar reconstruction (MPR) by chest CT showing a mass approximately $1.3 \mathrm{~cm}$ in diameter at the onset of right upper lobar bronchus; b Virtual bronchoscopy showing a neoplasm protruding from the right upper lobar bronchus to the main bronchus

lymph nodes around the upper lobar bronchus $(\# 12 \mathrm{u})$ were removed, and the right main bronchus and the secondary carina were mobilized circumferentially. Then, an R0 deeper wedge resection of the main bronchus where the tumor located was made, with the secondary carina reconstructed and the upper lobe restored (Fig. 2). No air leak was found by water-seal test.

The pathological examination was compatible to the recurrence of mucoepidermoid carcinoma of low grade with no lymph node involvement. The postoperative course was uneventful. He remained free of tumor 18 months after surgery (Fig. 3).

\section{Discussion}

Since the first report of bronchoplasty [2], a variety of surgical technical modifications has been reported, and with the development of surgical technique, the morbidity and mortality has been decreasing in these years to an acceptable level [3-5]. The surgical technique described here differed from the previous methods in the following aspects: (1), wedge but not sleeve resection was made at the secondary carina; (2), the upper lobe was divided and then restored by the secondary carina reconstruction with the tumor resected.

Compared to the sleeve resection of the right main bronchus, the present method was supposed to be easier, less time-consuming and less technique demanding, with more blood-supply preserved; Compared to sleeve lobectomy, the present method preserved pulmonary parenchymal; Compared to wedge resection of the bronchus without secondary carina reconstruction, in which too short proximal and distal incision line made angular

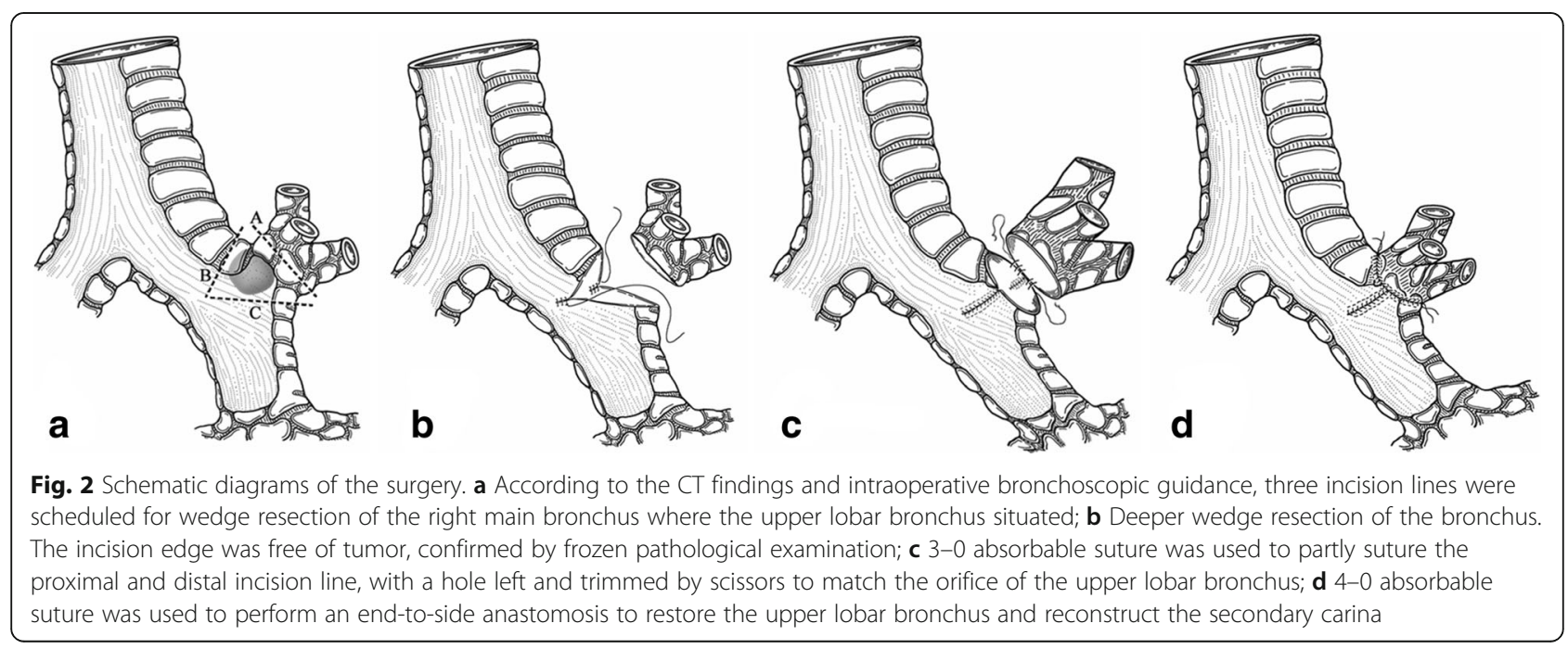




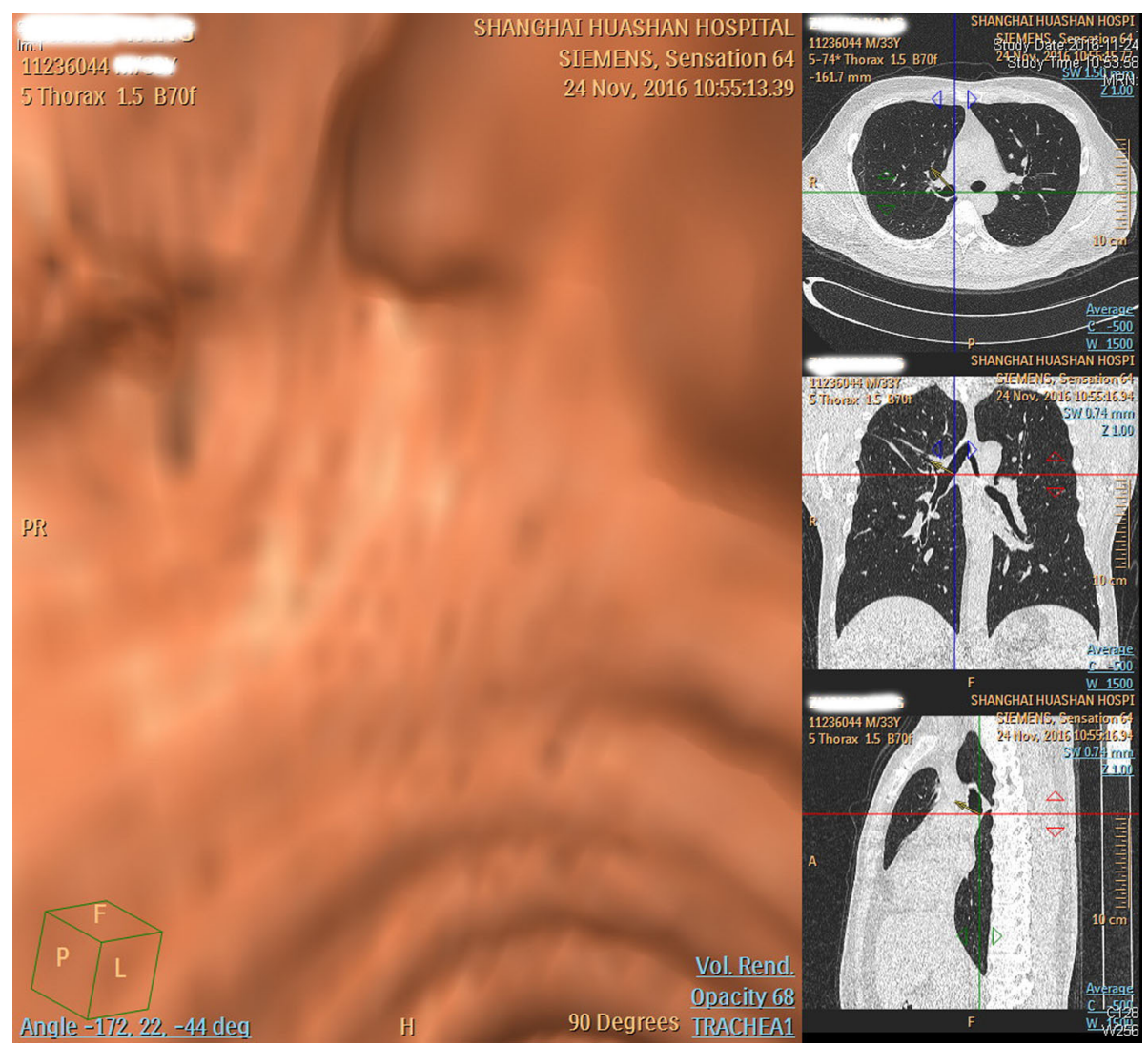

Fig. 3 Postoperative virtual bronchoscopy by chest CT showing the anastomotic region where the tumor developed preoperatively and multi-planar reconstruction (MPR) by chest CT showing patency of the right main bronchus, intermediate bronchus and upper lobar bronchus without any evidence of recurrence and atelectasis

deformity after suturing, the deeper wedge resection and subsequent reconstruction was free of such concern due to the orifice left in the lateral wall of the main bronchus for the restoration of the upper lobe.

The key points of the method were the incision lines of wedge resection. Firstly, the incision line of bronchotomy should be determined with intra-operative bronchoscopic guidance. The coronal scan could also play a role in determining the incision lines. Secondly, three incision edges should be checked respectively by frozen examination to ensure no involvement of tumor cell. In case of tumor cell involvement in incision line A or B (Fig. 2a), deeper wedge resection should be added or abandoned, substituted by sleeve bronchial resection. In case of tumor cell involvement in incision line $C$, further upper lobectomy should be considered.

\section{Conclusion}

As a modification of surgical technique, our method is less technique-demanding and less time-consuming than previously reported method. It is eligible and thus an option for small-size low-grade neoplasms located at the orifice of upper lobar bronchus with invasion to main bronchus but intact median wall of main bronchus.

\section{Abbreviation \\ CT: Computed tomography; VATS: Video-assisted thoracoscopic surgery}

\section{Acknowledgement}

Not applicable.

\section{Funding}

None.

\section{Availability of data and materials}

The data supporting the conclusions of this article are included within the article.

\section{Authors' Contribution}

CX performed the surgery, HD assisted in the surgery, WA wrote the report, and WS drew the pictures and revised the manuscript. All authors read and approved the final manuscript.

\section{Competing interests}

The authors declare that they have no competing interests.

\section{Consent for publication}

Written informed consent was obtained from the patient for publication of this case report and any accompanying images. A copy of the written consent is available for review by the Editor-in-Chief of this journal. 


\section{Ethics approval and consent to participate}

Not required.

\section{Publisher's Note}

Springer Nature remains neutral with regard to jurisdictional claims in published maps and institutional affiliations.

Received: 27 February 2017 Accepted: 6 June 2017

Published online: 13 June 2017

\section{References}

1. Tapias LF, Ott HC, Mathisen DJ. Complications Following Carinal Resections and Sleeve Resections. Thorac Surg Clin. 2015;25:435-47.

2. Paulson DL, Shaw RR. Bronchial anastomosis and bronchoplastic procedures in the interest of preservation of lung tissue. J Thorac Cardiovasc Surg. 1955;29:238-59.

3. Kotoulas C, Lazopoulos G, Foroulis C, Kostantinou M, Tomos P, Lioulas A. Wedge resection of the bronchus: an alternative bronchoplastic technique for preservation of the lung tissue. Eur J Cardiothorac Surg. 2001;20:679-83.

4. Lucchi M, Melfi F, Ribechini A, et al. Sleeve and wedge parenchyma-sparing bronchial resections in low-grade neoplasms of the bronchial airway. J Thorac Cardiovasc Surg. 2007:134(2):373-7.

5. Gonzalez-Rivas D, Yang Y, Sekhniaidze D, Stupnik T, Fernandez R, Lei J, Zhu $Y$, Jiang G. Uniportal video-assisted thoracoscopic bronchoplastic and carinal sleeve procedures. J Thorac Dis. 2016;8 Suppl 2:S210-22.

Submit your next manuscript to BioMed Central and we will help you at every step:

- We accept pre-submission inquiries

- Our selector tool helps you to find the most relevant journal

- We provide round the clock customer support

- Convenient online submission

- Thorough peer review

- Inclusion in PubMed and all major indexing services

- Maximum visibility for your research

Submit your manuscript at www.biomedcentral.com/submit
Biomed Central 